\title{
PENGARUH PREGNANCY CLASS TERHADAP PENINGKATAN PENGETAHUAN DAN KETERAMPILAN IBU HAMIL TENTANG KESEHATAN IBU DAN ANAK (KIA)
}

\author{
Johani Dewita Nasution ${ }^{1}$, Sri Siswati ${ }^{2}$ \\ Poltekkes Kemenkes Medan Jurusan Keperawatan \\ Email, ${ }^{1}$ jodewita_naufal@yahoo.com, : 2srisiswati20@gmail.com
}

\begin{abstract}
Today's health development in Indonesia is still prioritized on efforts to improve the health status of mothers and children, especially for the groups most vulnerable to the health of pregnant women, childbirth and perinatal infants. Pregnancy Class is a means to learn together about health for pregnant women, in the form of face to face. This study aims to identify the knowledge and skills of pregnant women regarding MCH before, after and one month after participating in the Pregnancy Class in the Muliorejo Community Health Center in 2020. The research design used in this research is quasy-experimental. Pregnancy Class in this research observation was carried out 3 times, namely pre test / before treatment, post test / after treatment and one month after treatment carried out in 7 pregnancy class groups, each group implementation for 3 weeks with a frequency of once a week within 120 minutes in pregnant women with gestational age of 20-32 weeks. The research subjects taken were 42 people, but participants who met the inclusion criteria were 35 pregnant women. Based on the results of data analysis using paired t-test, it shows that the difference between the scores of knowledge and skills before and after the intervention shows a significant difference $p=0.001(\alpha<0.05)$. While the difference in knowledge after the intervention and one month after the intervention showed no significant difference $p=0.378(\alpha>0.05)$, this proved that there was no difference between knowledge after intervention and knowledge one month after intervention. For the difference in skills after the intervention with one month after the intervention showed a significant difference $p=0.012(\alpha<0.05)$, this proved that there was a difference between after the intervention and one month after the intervention. The conclusions from the findings of this study indicate that the Pregnancy Class has a significant effect on increasing the knowledge and skills of pregnant women about maternal and child health (KIA).
\end{abstract}

Keywords: pregnancy class, knowledge, skills, characteristics of pregnant women, mother and child health

\begin{abstract}
ABSTRAK
Pembangunan kesehatan di Indonesia dewasa ini masih diprioritaskan pada upaya peningkatan derajat kesehatan ibu dan anak, terutama pada kelompok yang paling rentan kesehatan ibu hamil, bersalin dan bayi masa perinatal.Pregnancy Class merupakan sarana untuk belajar bersama tentang kesehatan bagi ibu hamil, dalam bentuk tatap muka. Penelitian ini bertujuan untuk mengidentifikasi pengetahuan dan keterampilan ibu hamil mengenai KIA sebelum, sesudah dan satu bulan setelah mengikuti Pregnancy Class di wilayah Puskesmas Muliorejo tahun 2020. Desain penelitian yang digunakan dalam penelitian ini adalah quasy-eksperiment. Pregnancy Class dalam dalam penelitian ini observasi dilakukan sebanyak 3 kali yaitu pre test/ sebelum perlakuan, post test /sesudah perlakuan dan satu bulan sesudah perlakuan dilakukan pada 7 kelompok pregnancy class, masing-masing kelompok pelaksanaannya selama 3 minggu dengan frekuensi sekali seminggu dalam waktu 120 menit pada ibu hamil dengan usia kehamilan 20-32 minggu. Subjek penelitian yang diambil adalah 42 orang tetapi peserta yang memenuhi criteria inklusi berjumlah 35 ibu hamil. Berdasarkan hasil analisa data dengan uji paired t-test menunjukkan bahwa selisih antara skor pengetahuan dan keterampilan sebelum dan sesudah intervensi menunjukkan adanya perbedaan yang signifikan $\mathrm{p}=0,001(\alpha<0,05)$. Sedangkan selisih pengetahuan sesudah intervensi dengan satu bulan sesudah intervensi menunjukkan tidak ada perbedaan yang signifikan $p=0,378(\alpha>0,05)$, hal ini membuktikan tidak ada beda antara pengetahuan sesudah intervensi dengan pengetahuan satu bulan sesudah intervensi. Untuk selisih keterampilan sesudah intervensi dengan satu bulan sesudah intervensi menunjukkan adanya perbedaan yang signifikan $p=0,012(\alpha<0,05)$, hal ini membuktikan ada beda antara sesudah intervensi dan satu bulan sesudah intervensi. Kesimpulan dari penemuan penelitian ini menunjukkan bahwa Pregnancy Class berpengaruh signifikan terhadap peningkatan pengetahuan dan keterampilan ibu hamil tentang kesehatan ibu dan anak (KIA).
\end{abstract}

Kata kunci: pregnancy class, pengetahuan, keterampilan, karakteristik ibu hamil, kesehatan ibu dan anak 


\section{PENDAHULUAN}

Tingginya tingkat kematian ibu yang berkaitan dengan kehamilan dan persalinan merupakan salah satu masalah besar di Indonesia, karena angka kematian ini menunjukkan gambaran derajat kesehatan disuatu wilayah, sebagai gambaran indeks pembangunan manusia Indonesia, sehingga pelayanan kesehatan ibu dan anak menjadi prioritas utama dalam pembangunan kesehatan di Indonesia. Sekitar 25-50\% kematian perempuan usia subur disebabkan oleh hal yang berkaitan dengan kehamilan. WHO memperkirakan setiap tahun terjadi 210 juta kehamilan diseluruh dunia. Dari jumlah ini 20 juta perempuan mengalami kesakitan sebagai akibat kehamilan, sekitar 8 juta mengalami komplikasi yang mengancam jiwa, dan lebih dari 500.000 meninggal pada 2005. Sebanyak 50\% terjadi di negara-negara Asia Selatan dan Tenggara, termasuk Indonesia (Saifuddin, 2010). Dalam hal ini, hampir semua negara anggota telah berupaya menurunkan kematian ibu dan anak dengan meningkatkan penyediaan pelayanan kelahiran oleh tenaga kesehatan terampil. Puskesmas Muliorejo adalah salah satu Puskesmas yang ada di wilayah Kabupaten Deli Serdang yang mempunyai wilayah kerja 7 desa, pencapaian program KIA tahun 2018, kunjungan antenatal (K1) 84,9\% (K4) 55,1\% dan Linakes $80,9 \%$ dari data tersebut menunjukkan bahwa selama pencapaian K4 di Puskesmas Muliorejo belum mencapai target. Data kematian ibu untuk Puskesmas Muliorejo dalam kurun waktu 4 tahun terakhir (20142018) tidak ada kematian, kematian bayi pada tahun 2017 tedapat 5 kasus, tahun 2018 terdapat 7 kasus, dengan penyebab kematian karena BBLR dan Asfiksia (Profil Dinas Kesehatan Kabupaten Deli Serdang, 2018).

Upaya akselerasi penurunan AKI diantaranya adalah dengan peran serta masyarakat dengan kegiatan KIE berupa penyuluhan tentang kesehatan ibu kepada berbagai sasaran termasuk ibu hamil, suami dan mertua, memanfaatkan media cetak dan elektronik untuk kampanye tentang kesehatan ibu. Dalam konvensi hak-hak anak, semua anak sejak dari dalam kandungan mempunyai hak atas kelangsungan hidup, perkembangan dan mendapat perlindungan. Pemantauan intensif pada ibu hamil untuk kesehatan ibu hamil dan persiapan persalinan. Hal ini dapat dilaksanakan secara efektif dan efisien melalui pemberdayaan masyarakat, kemitraan petugas kesehatan dengan masyarakat serta mewujudkan kesadaran, kemandirian keluarga untuk menjaga kesehatan ibu dan anak (Kemenkes RI, 2017).

Pengetahuan atau kognitif merupakan domain yang sangat penting untuk tebentuknya tindakan seseorang (Over Behaviour). Pengetahuan seseorang dipengaruhi oleh pendidikan, mass media/ informasi, sosial budaya dan ekonomi, lingkungan, pengalaman dan usia (Notoatmodjo, 2014).

Salah satu alat program kesehatan yang diharapkan turut berperan dalam menurunkan angka kesakitan dan kematian akibat kehamilan, persalinan dan nifas dalam meningkatkan pengetahuan dan keterampilan ibu hamil, keluarga dan masyarakat adalah melalui buku Kesehatan Ibu dan Anak (KIA), yang merupakan kumpulan materi standar penyuluhan, informasi serta catatan tentang gizi, kesehatan ibu dan anak. Manfaat buku KIA diantaranya adalah sebagai alat komunikasi dan penyuluhan bagi ibu, keluarga dan masyarakat (Kemenkes, 2017).

Dalam Niaty (2010), menurut hasil survey cepat tahun 2014 tentang penggunaan buku KIA di NTB dan hasil penelitian yang dilakukan oleh Kusumawati (2008) tentang pengaruh pemanfaatan buku KIA di Padang Pariaman dan Tanah Datar Sumatera Barat, mengungkapkan bahwa tidak semua ibu mau/ bisa membaca buku KIA, sehingga ibu-ibu hamil sulit memahami/ mengerti isi dari buku KIA, sementara diketahui bersama bahwa pemanfaatan buku KIA memiliki potensi untuk meningkatkan perilaku perawatan diri ibu dan memanfaatkan pelayanan KIA.

Pendidikan kesehatan ibu dan anak yang diberikan kepada ibu yang lazim dilaksanakan sampai sekarang lebih banyak berupa penyuluhan melalui konsultasi perorangan atau per kasus yang diberikan pada waktu ibu datang memeriksakan kandungan atau memeriksakan bayi atau balita. Penyuluhan seperti diatas baik untuk menangani kasus per kasus, namun masih memiliki beberapa kelemahan antara lain pengetahuan yang diperoleh terbatas pada masalah kesehatan yang alami, penyuluhan yang diberikan tidak terkoordinir sehingga ilmu kesehatan yang diberikan kepada ibu hanyalah pengetahuan yang dimiliki oleh petugas saja, karena tidak ada suatu tim dalam penyuluhan, 
tidak ada rencana kerja sehingga tidak ada kunjungan dari lintas sektor dan lintas program, pelaksanaan penyuluhan tidak berkala dan tidak berkesinambungan. Untuk mengatasi kelemahan-kelemahan diatas dan memudahkan ibu hamil memahami isi buku KIA dan bagaimana cara menggunakan buku KIA, direncanakan pendidikan untuk kelas ibu hamil, yang lebih menyeluruh dan sistematis serta dapat dilaksanakan secara berkala dan berkesinambungan. Kegiatan yang direncanakan ialah pendidikan dalam bentuk tatap muka dalam kelas yang diikuti dengan diskusi antara ibu dan petugas, yang dinamakan "Pregnancy Class".

Pregnancy Class merupakan sarana untuk belajar bersama tentang kesehatan bagi ibu hamil, dalam bentuk tatap muka yang bertujuan meningkatkan pengetahuan dan keterampilan ibu-ibu mengenai kehamilan, perawatan kehamilan, perencanaan persalinan dan pencegahan komplikasi, persalinan, perawatan nifas, perawatan bayi, mitos, penyakit menular dan akte kelahiran. Dengan kegiatan ini diharapkan akan muncul kelompok para ibu yang benar-benar memahami kesehatan diri dan bayinya, mampu menyiapkan diri menghadapi gangguan selama kehamilan serta mampu menyiapkan diri dan keluarganya selama proses persalinan dan juga mampu merawt bayinya dengan baik (Kemenkes, 2017).

Puskesmas Muliorejo merupakan salah satu Puskesmas yang memulai melaksanakan kelas ibu hamil pada tahun 2014, pelaksanaan kelas ibu hamil dilaksanakan di Puskesmas sebagai percontohan untuk desa-desa di wilayah kerja Puskesmas Pembantu, untuk selanjutnya semua desa diharapkan ikut melaksanakan kegiatan serupa. Dari beberapa desa yang melaksanakan kelas ibu hamil, pelaksanaannya belum berjalan dengan optimal/ belum sesuai dengan ketentuan pada petunjuk sebagian besar perawatan bayi baru lahir seperti memandikan dan merawat tali pusat hingga berusia 7 hari atau sampai tali pusatnya lepas diserahkan kepada dukun bayi. Selain itu banyak dijumpai keluhan ibu bayi mengalami payudara bengkak/ puting susu lecet yang disebabkan oleh perlekatan menyusui yang tidak benar. Tujuan diselenggarakan pregnancy class adalah dapat dijadikan sarana belajar untuk meningkatkan pengetahuan tentang perilaku positif ibu hamil yang dibuktikan dengan meningkatkan kunjungan pemeriksaan ke KIA serta pencapaian persalinan oleh tenaga kesehatan.

\section{METODOLOGI PENELITIAN}

Desain penelitian yang digunakan dalam penelitian adalah rancangan QuasyEksperiment yaitu rancangan yang berupaya mengungkapkan hubungan sebab akibat dengan tanpa melibatkan kelompok kontrol (Nursalam, 2003). Penentuan besar sampel dilakukan dengan menggunakan total sampling. Sehingga diperoleh besar sampel adalah 42 orang. Selama penelitian berlangsung terdapat responden yang gugur sebanyak 7 orang sehingga sampel menjadi 35 orang. Dalam penelitian ini observasi dilakukan sebanyak 3 kali yaitu pre test/sebelum perlakuan, post test/sesudah perlakuan dan satu bulan sesudah perlakuan untuk mengetahui pengaruh intervensi pelatihan pregnancy class terhadap perubahan pengetahuan dan keterampilan ibu hamil. Kemudian data penelitian ini di analisa dengan uji statistik deskriptif dan inferensial.

\section{Hasil Penelitian}

Tabel 1. Karakteristik Responden

Karakteristik

\begin{tabular}{lc}
\hline Umur dikategorikan & 2 \\
$<\mathbf{2 0}$ tahun & 29 \\
$\mathbf{2 0}$ - $\mathbf{3 5}$ tahun & 4 \\
$\mathbf{>} \mathbf{3 5}$ tahun & $\mathbf{3 5}$ \\
Total & \\
Pekerjaan & \\
Bekerja & 13 \\
Tidak bekerja & 22 \\
\hline
\end{tabular}

Persentase

$5,7 \%$

$82,9 \%$

$11,4 \%$

$100 \%$ 
Vol. 16 No. 1 Januari - April 2021

\begin{tabular}{lcc}
\hline Total & $\mathbf{3 5}$ & $100 \%$ \\
\hline Tingkat Pendidikan & & \\
\hline Rendah, $\leq$ SMP & 25 & $\mathbf{7 1 , 4} \%$ \\
Tinggi, > SMP & 10 & $\mathbf{2 8 , 6} \%$ \\
\hline Total & $\mathbf{3 5}$ & $100 \%$ \\
\hline Jumlah Kehamilan/Paritas & & \\
Hamil ke-1 & 18 & $\mathbf{5 1 , 4} \%$ \\
Hamil > & 17 & $\mathbf{4 8 , 6} \%$ \\
\hline Total & $\mathbf{3 5}$ & $100 \%$ \\
\hline Umur Kehamilan & & \\
Trimester II, 20-24 minggu & 13 & $\mathbf{3 7 , 1} \%$ \\
\hline Trimester III, 25-32 minggu & 22 & $\mathbf{6 2 , 9} \%$ \\
\hline Total & 35 & $100 \%$ \\
\hline
\end{tabular}

Berdasarkan penelitian yang dilakukan, didapatkan sebagian besar ibu hamil pada umur 20-35 tahun, berdasarkan pekerjaan, sebagian besar ibu hamil tidak bekerja, dari ibu hamil yang bekerja antara lain bekerja sebagai buruh, pedagang, wiraswasta dan petani. Pada distribusi tingkat pendidikan didapatkan sebagian besar ibu hamil dengan pendidikan rendah atau $\leq$ SMP, sedangkan berdasar jumlah kehamilan/ paritas, pada penelitian ini lebih dari setengah ibu hamil dengan paritas pertama, untuk umur kehamilan ibu dalam penelitian ini menunjukkan bahwa sebagian besar ibu hamil pada Trimester III ( 25-32 minggu).

Tabel 4.2 Distribusi Frekuensi Menurut Keterpaparan Informasi Pengetahuan KIA Dan Sumber Informasi

Jenis Informasi Dapat Informasi

\begin{tabular}{lcccc}
\hline & Ya & \% & Tidak & \% \\
Informasi Pengetahuan & & & & \\
Perubahan tubuh pada bumil & 28 & 80 & 7 & 20 \\
Keluhan saat hamil & 33 & 94,3 & 2 & 5,7 \\
Perawatan kehamilan & 26 & 74,3 & 9 & 25,7 \\
Persalinan & 24 & 68,6 & 11 & 31,4 \\
Perawatan Nifas & 19 & 54,3 & 16 & 45,7 \\
Perawatan bayi & 25 & 71,4 & 10 & 28,6 \\
Mitos & 33 & 94,3 & 2 & 5,7 \\
Penyakit menular & 14 & 40 & 21 & 60 \\
Akte Kelahiran & 32 & 91,4 & 3 & 8,6 \\
& & & & \\
Sumber Informasi & & & & \\
Teman & 24 & 68,6 & 11 & 31,4 \\
Orang tua & 32 & 91,4 & 3 & 8,6 \\
Dukun & 3 & 8,6 & 32 & 91,4 \\
Tenaga Kesehatan & 23 & 65,7 & 12 & 34,3 \\
Radio & 0 & 0 & 35 & 100 \\
Televisi & 4 & 11,4 & 31 & 88,6 \\
Buku, koran, majalah & 17 & 48,6 & 18 & 51,4 \\
Internet & 1 & 2,9 & 34 & 97,1 \\
\hline
\end{tabular}


Tabel 4.3 Distribusi Frekuensi Menurut Keterpaparan Informasi Keterampilan KIA Dan Sumber Informasi

\begin{tabular}{lcccr}
\hline \multicolumn{1}{c}{ Jenis Informasi } & \multicolumn{3}{c}{ Dapat Informasi } \\
\hline Informasi Keterampilan & Ya & \% & Tidak & \% \\
Cara memandikan bayi & & & & \\
Mengenakan Popok & 21 & 60 & 14 & 40 \\
Perawatan Tali Pusat & 25 & 71,4 & 10 & 28,6 \\
Teknik Menyusui & 11 & 31,4 & 24 & 68,6 \\
Senam Hamil & 21 & 60 & 14 & 40 \\
& 1 & 2,9 & 34 & 97,1 \\
Sumber Informasi & & & & \\
Teman & & & & \\
Orang tua & 8 & 22,9 & 27 & 77,1 \\
Dukun & 15 & 42,9 & 20 & 57,1 \\
Tenaga Kesehatan & 17 & 48,6 & 18 & 51,4 \\
Radio & 10 & 28,6 & 25 & 71,4 \\
Televisi & 0 & 0 & 35 & 100 \\
Buku, koran, majalah & 0 & 0 & 35 & 100 \\
Internet & 2 & 5,7 & 33 & 94,3 \\
\hline
\end{tabular}

Tabel 4.4 Distribusi Ibu Hamil Menurut Pengetahuan dan keterampilan Sebelum, Sesudah Intervensi Dan Satu Bulan Sesudah Intervensi Penyuluhan KIA

\begin{tabular}{lcccrr}
\hline \multicolumn{1}{c}{ Variabel } & Mean & Median & SD & Min-Max & \multicolumn{1}{c}{ 95\%CI } \\
\hline $\begin{array}{l}\text { Sebelum Intervensi Penyuluhan } \\
\text { Pengetahuan (Skala 0-56) }\end{array}$ & & & & & \\
Keterampilan (Skala 0-104) & 35,5 & 37 & 7,8 & $19-47$ & $32,9-38,2$ \\
& 21,2 & 19 & 9,1 & $10-41$ & $18,1-24,3$ \\
Sesudah Intervensi & & & & & \\
Pengetahuan (Skala 0-56) & 47,8 & 51 & 8,5 & $24-56$ & $44,8-50,7$ \\
Keterampilan (Skala 0-104) & 95,7 & 97 & 5,9 & $82-104$ & $93,7-97,7$ \\
Satu Bulan Sesudah Intervensi & & & & & \\
Pengetahuan (Skala 0-56) & & & & & \\
Keterampilan (Skala 0-104) & 47,2 & 49 & 8,3 & $21-56$ & $90,6-96$ \\
& 93,3 & 95 & 7,9 & $69-104$ & \\
\hline
\end{tabular}

Tabel 4.5 Selisih Skor Pengetahuan Dan Keterampilan Ibu Hamil Mengenai KIA Sebelum Dengan Sesudah Intervensi, Sesudah Dengan Satu Bulan Sesudah Intervensi Pregnancy Class

\begin{tabular}{|c|c|c|c|c|c|}
\hline Variabel & $\overline{\text { Mean }}$ & $\mathrm{SD}$ & Min-Max & $95 \% \mathrm{CI}$ & Nilai $p$ \\
\hline \multicolumn{6}{|c|}{ Sebelum-sesudah intervensi } \\
\hline Pengetahuan & 12,1 & 5,17 & $2-26$ & $14,01-10,5$ & $<0,001$ \\
\hline Keterampilan & 74,5 & 8,96 & $55-89$ & $77,6-71,4$ & $<0,001$ \\
\hline \multicolumn{6}{|c|}{ Sesudah intervensi-1 bulan sesudah intervensi } \\
\hline Pengetahuan & 0,6 & 3,97 & $(-11)-11$ & $0,76-1,96$ & 0,378 \\
\hline Keterampilan & 2,4 & 6,32 & $(-11)-16$ & $0,23-4,67$ & 0,012 \\
\hline
\end{tabular}




\section{Pembahasan}

Berdasarkan hasil penelitian diketahui hasil mean, nilai minimum dan maksimum pada satu bulan sesudah pelatihan pregnancy classterjadi penurunan dibanding sesudah intervensi pregnancy classHasil uji Paired samples T-test menunjukkan $p=0,012$ $(p<0,05)$ sehingga dapat disimpulkan bahwa ada perbedaan yang signifikan antara keterampilan ibu hamil sesudah intervensi dan satu bulan sesudah mengikuti pelatihan pregnancy class.

Hal ini memberikan arti bahwa pelatihan mengenai keterampilan ibu hamil meliputi cara memandikan bayi, memakaikan popok, perawatan tali pusat, teknik menyusui dan senam hamil perlu disampaikan lagi pada ibu hamil karena untuk merubah perilaku tidak dapat dilakukan secara instan. Terbukti pada skor post tes keterampilan nilainya tinggi dibanding pretes karena ibu hamil baru saja mendapat materi dan langsung praktek menggunakan alat peraga. Namun dengan berjalannya waktu pada saat pengambilan data satu bulan sesudah pelatihan ada beberapa ibu hamil kembali ke perilaku semula terutama ibu dengan kehamilan lebih dari satu. Kebanyakan ibu hamil dalam praktek memandikan melewatkan item membersihkan kotoran dan air kencing dan bayi langsung dimasukkan ke dalam bak mandi, untuk memakaikan popok sebagian besar ibu hamil sudah melaksanakan dengan baik.Untuk perawatan tali pusat ada beberapa ibu yang masih menggunakan betadin/alkohol, untuk teknik menyusui ibu yang sudah pernah menyusui masih kembali ke kebiasaan lama dengan melakukan tekanan pada payudara terlebih dahulu sebelum menyusui padahal tindakan ini bisa merusak lobus -lobus pada payudara ibu, dan teknik perlekatan yang belum tepat.

\section{KESIMPULAN DAN SARAN Kesimpulan}

1. Pelaksanaan pregnancy class di Puskesmas Muliorejo Kabupaten Deli Serdang tahun 2020 berpengaruh terhadap peningkatan pengetahuan dan keterampilan ibu hamil mengenai Kesehatan Ibu dan Anak dilihat dengan adanya kenaikan yang signifikan pada nilai rata-rata.

2. Setelah dilakukan pregnancy class ratarata skor pengetahuan naik sebanyak 47,8 (skala 0-56), rata-rata keterampilan naik sebesar 95,7 (skala 0-104), sedangkan ratarata pada satu bulan sesudah mengikuti pregnancy class untuk pengetahuan turun dibanding setelah pelatihan yaitu 47,2 (skala 0-56), rata- rata keterampilan 93,3 (skala0-104).

3. Perbedaan nilai sebelum dan sesudah pelatihan pregnancy class untuk pengetahuan sebesar 12,2, keterampilan sebesar 74,5. Sedangkan perbedaan nilai sesudah pelatihan dengan satu bulan sesudah pelatihan pada pengetahuan sebesar 0,6, keterampilan sebesar 2,4.

\section{Saran}

\section{Bagi Dinas Kesehatan Kabupaten Deli} Serdang

a. Pregnancy Class terbukti meningkatkan pengetahuan dan keterampilan ibu hamil mengenai kesehatan ibu dan anak, untuk itu diharapkan agar setiap puskesmas melaksanakan pregnancy class sebagai kegiatan rutin seperti kegiatan posyandu dan mengarahkan agar kegiatan tersebut bersifat mandiri dari masyarakat.

b. Diharapkan melakukan monitoring dan evaluasi kegiatan pregnancy class karena selama ini belum ada pencatatan dan pelaporan mengenai kegiatan tersebut ke dinas.

c. Diharapkan fasilitator kabupaten mengadakan pelatihan bagi bidan desa agar pelaksanaan pregnancy class sesuai dengan standar dan prosedurnya.

\section{Bagi Institusi}

a. Diharapkan program pregnancy class tetap dilanjutkan di puskesmas sebagai wadah untuk meningkatkan pengetahuan dan keterampilan ibu hamil dan dikembangkan secara luas dan dilanjutkan ke kelas ibu balita.

b. Diharapkan dalam pregnancy class tetap memberikan materi keterampilan seperti memandikan bayi, memakaikan popok, perawatan tali pusat, teknik menyusui, senam hamil dan keterampilan lainnya, karena terbukti dapat menambah pengetahuan dan keterampilan ibu hamil sebagai bekal dalam perawatan anak.

c. Untuk bidan diharapkan dapat melaksanakan dan mengembangkan 
pregnancy class di desa binaan masingmasing serta senantiasa meningkatkan pengetahuan dan keterampilan agar dapat memberikan pelayanan kesehatan yang berkualitas kepada masyarakat.

d. Agar mengadakan koordinasi dengan pihak kecamatan (PKK) sehingga pelaksanaan pregnancy class dapat merupakan kegiatan mandiri dari desa dan merupakan pengembangan pemberdayaan masyarakat tanpa ketergantungan alokasi dana dari puskesmas, mengingat pentingnya pregnancy class untuk peningkatan pengetahuan dan keterampilan ibu hamil.

\section{Bagi Keilmuan}

Diharapkan dilaksanakan penelitian lanjutan tentang pregnancy class yang lebih berkualitas misalnya dengan menggunakan desain berupa true experiment design, menggunakan populasi yang lebih luas dan faktorfaktor lain yang belum sempat diteliti karena keterbatasan peneliti, mengingat pregnancy class merupakan salah satu program pemerintah terbaru di bidang kesehatan yang terbukti efektif dapat meningkatkan pengetahuan dan keterampilan dalam upaya menekan morbiditas dan mortalitas pada ibu dan bayi.

\section{DAFTAR PUSTAKA}

Adawiyah, E. 2010. Faktor-faktor yang berhubungan dengan kelangsungan pemeriksaan kehamilan K4 di Kabupaten Bogor tahun 2000 (analisis data sekunder survey cepat studi faktorfaktor yang berhubungan dengan morbiditas bayi di Kabupaten Bogor tahun 2000). Skripsi. Depok: FKM UI

Arikunto, S, 2010, Manajemen Penelitian. Jakarta: Rineka Cipta

Depkes RI. 2015. Kajian Kematian Ibu dan Anak di Indonesia, Jakarta: Depkes RI

2014. KIE Safe Motherhood di Indonesia, Departemen Kesehatan, Jakarta.
2017. Leaflet Kelas Ibu Hamil. Departemen Kesehatan RI kerja sama dengan Japan International Cooperation $\operatorname{Agency}(J I C A)$

2016.MateriAjarpenurunanKematianIb udanBayiBaruLahir. Jakarta: Depkes RI

2015. Panduan Pelaksanaan Strategi Making Pregnancy Safer (MPS) dan Child Survival. Departemen KesehatanJakarta

Depkes RI \& JICA. 2016. Pedoman Umum Manajemen Penerapan Buku KIA. Jakarta: Depkes RI

Depkes RI, 2017. Pedoman Pelaksanaan Kelas Ibu Hamil. Jakarta : Departemen Kesehatan RI

, 2017. Pedoman Umum Manajemen Kelas Ibu Hamil. Jakarta : Departemen KesehatanRI

. 2016a. Pedoman Pemantauan Wilayah Setempat Kesehatan Ibu dan Anak (PWS KIA), JakartaRI.

.2016.PetunjukTeknisPenggunaanBuku KesehatanIbudanAnak. Jakarta: Depkes RI

,2016. Pegangan Fasilitator Kelas Ibu Hamil. Jakarta: Departemen KesehatanRI

,2016. Pelatihan Kelas Ibu Hamil. Jakarta : Departemen Kesehatan RI - 2017. Upaya akselerasi penurunan Angka Kematian Ibu. Dirjen Bina Kesehatan Masyarakat,Jakarta

2016. Status Kesehatan Masyarakat Berbasis Gender Fakta dari Survei Kesehatan Nasional. Jakarta: DepkesRI

Depkes RI, 2016. Pelatihan Klinik Asuhan Persalinan Normal. Jakarta: Departemen Kesehatan RI

Depkes RI. 2014. Program Safe Motherhood di Indonesia, Departemen Kesehatan,Jakarta.

Hastuti,dkk.2011.EfektifitasPelatihanKelasIbu HamilUntukMeningkatkan Pengetahuan, Sikap, Keterampilan Dan 


\section{Vol. 16 No. 1 Januari - April 2021}

Kunjungan Antenatal Care.Journal Suara Forikes

Kementrian Kesehatan RI, 2010. Direktorat Jenderal Bina Kesehatan Masyarakat, Pedoman Pelayanan Antenatal Terpadu, Jakarta

Kusumayati, A. 2008. The Effect Of Maternal and Child Health Handbook Utilization in West Sumatera, Indonesia. Doktoral Dissertation, Ossaka University Graduate School of Human Sciences, 2008

Koblinsky, M. 2017. Kesehatan wanita: sebuah perspektif global. Yogyakarta: Gajah Mada University press.

Martaadisoebrata. 2015. Bunga Rampai Obstetri dan Ginekology Sosial. Yayasan Bina Pustaka Sarwono, Jakarta

Notoatmodjo, S. 2015. Ilmu Kesehatan Masyarakat. Jakarta : Rineka Cipta.

2017b. Promosi Kesehatan dan Ilmu Perilaku. Jakarta : Rineka Cipta.

_ 2015. Metodologi Penelitian Kesehatan. Jakarta: RinekaCipta

Romlah, S. 2009. Pengaruh Kelas Ibu Hamil Terhadap Perilaku dalam Perencanaan P4K di Kabupaten Garut Jawa Barat 2009. Tesis. Program Pasca Sarjana Fakultas Kesehatan Masyarakat Universitas Indonesia. Depok 